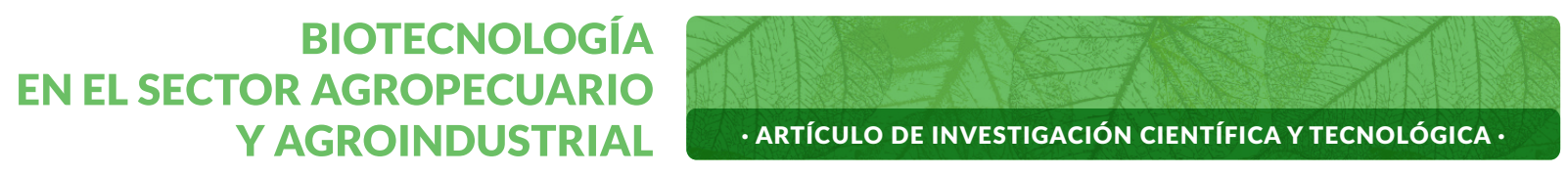

\title{
Evaluación del efecto antifúngico de metabolitos de cultivos bioprotectores: aplicación en derivados lácteos*
}

\section{Evaluation of the antifungal effect of metabolites of bioprotective cultures: dairy food applications}

\section{Avaliação do efeito antifúngico de metabólitos de culturas bioprotetoras: sua aplicação em derivados lácteos}

\footnotetext{
Historial del Artículo

Recibido para evaluación: 12 de Septiembre 2019.

Aprobado para publicación: 1 de Mayo 2020.

*Título del proyecto de origen: Aplicación de bioprotectores en la industria láctea. Financiación: Alpina Productos Alimenticios S. A. Culminación. Julio de 2018

1 Alpina Productos Alimenticios S.A., Dirección de Investigación, Desarrollo e Innovación. Ph.D Ciencia y Tecnología de Alimentos. Sopó, Colombia. ORCID. https://orcid.org/00000002-1471-6312

2 Alpina Productos Alimenticios S.A., Dirección de Investigación, Desarrollo e Innovación. Ph.D Biociencia de los Alimentos. Sopó, Colombia. ORCID: https://orcid.org/0000-00020184-0541
}

Correspondencia: bernadette.klotz@alpina.com

Cómo citar este artículo: JAMES BETANCUR-LÓPEZ, MARÍA FERNANDA FLÓREZ, ANA MARÍA PÉREZ-O`BRIEN, NEIL VASQUEZ-ARAQUE, ANDRÉS MONTOYA-LÓPEZ. Clonación del cDNA codificante de las subunidades de la gonadotropina luteinizante de Pimelodus grosskopfii. Revista Biotecnología en el Sector Agropecuario y Agroindustrial, 18(2),2020.1525, DOI:http://dx.doi.org/10.18684/BSAA(18)15-25 


\section{RESUMEN}

Para garantizar la inocuidad y la vida útil de muchos alimentos procesados, la industria de alimentos ha hecho uso de conservantes artificiales que cada vez son más cuestionados y reemplazados por alternativas naturales como son los cultivos bioprotectores. Las bacterias ácido lácticas (BAL) y ácido propiónicas (BAP) son los grupos bacterianos más reconocidos por su acción antimicrobiana sobre bacterias patógenas y en menor grado sobre hongos. EI presente estudio evaluó la funcionalidad antifúngica de tres cepas de Lactobacillus casei, tres de L. rhamnosus y tres de Propionibacterium freudenreichii sobre aislados de Mucor circinelloides y Geotrichum candidum y el efecto de factores como la Pasteurización $\left(74^{\circ} \mathrm{C}, 3 \mathrm{~min}\right)$ y el medio de crecimiento de los cultivos bioprotectores (leche y BRFS) sobre esta. Los ensayos reto con cultivos bioprotectores sin y con tratamiento térmico realizados por triplicado en modelos lácteos (agar yogur) arrojaron los siguientes resultados de acuerdo con una escala cualitativa de crecimiento fúngico: (1) diferentes cepas de BAL y BAP divergieron en funcionalidad bioprotectora, (2) el tratamiento térmico eliminó o redujo sustancialmente el poder antifúngico de los cultivos con la excepción de P. freudenreichii subsp. shermanii BPL0082 y (3) los cultivos desarrollados en medio BRFS presentaron mayor capacidad de inhibición.

\section{ABSTRACT}

To guarantee the food safety and shelf life of many processed food products, the food industry has made use of artificial preservatives that are each time more questioned and replaced by natural alternatives such as bioprotective cultures. Lactic acid bacteria (LAB) and propionic acid bacteria (PAB) are bacterial groups recognized by their antimicrobial action against bacterial pathogens but their activity against fungi is lesser known. The present study evaluated the antifungal functionality of three strains Lactobacillus casei, three of L. rhamnosus, and three of Propionibacterium freudenreichii against isolates of Mucor circinelloides and Geotrichum candidum and the effect of factors like pasteurization $\left(74^{\circ} \mathrm{C}, 3 \mathrm{~min}\right)$ and culture media (milk and BRFS) on it. The challenge assays in dairy models (yogurt agar) produced the following results in accordance to a qualitative score scale of fungal growth: (1) different strains of $L A B$ and PAB differed in the bioprotective functionality, (2) the heat treatment eliminated or reduced substantially the antifungal power with the exception of P. freudenreichii subsp. shermanii BPL0082, and (3) the cultures developed in media BRFS exhibited greater inhibition capacity.

\section{RESUMO}

Para garantir a inocuidade e a vida útil de muitos alimentos processados, a indústria alimentícia faz uso de conservantres artificiais, que vêm sendo cada vez mais questionados e substituídos por alternativas naturais, como é o caso das culturas bioprotetoras. As bactérias ácido-láticas (BAL) e ácido-propiônicas (BAP) constituem os grupos bacterianos mais reconhecidos por sua ação antimicrobiana sobre bactérias patogênicas e, em menor grau, sobre os fungos. O presente estudo avaliou a funcionalidade antifúngica de três cepas de

\section{PALABRAS CLAVE:}

Bioprotección, Modelos lácteos, Mohos, Pasteurización.

\section{KEYWORDS:}

Bioprotection, Dairy models, Molds, Pasteurization.

\section{PALAVRAS-CHAVE:}

Bioproteção, Bolores, Modelos

lácteos, Pasteurização. 
Lactobacillus casei, três de L. rhamnosus e três de Propionibacterium freudenreichii sobre isolados de Mucor circinelloides e Geotrichum candidum, bem como o efeito de fatores como a pasteurização $\left(74^{\circ} \mathrm{C}, 3 \mathrm{~min}\right)$ e o meio de crescimento das culturas bioprotetoras (leite e BRFS) sobre ela. Os ensaios de desafio com culturas bioprotetoras com e sem tratamento térmico realizados por triplicado em modelos lácteos obtiveram os seguintes resultados de acordo com uma escala qualitativa de crescimento fúngico: (1) diferentes cepas de BAL e BAP divergem quanto à função bioprotetora, (2) o tratamento térmico eliminou ou reduziu o poder antifúngico com exceção da $P$. freudenreichii subsp. shermanii BPL0082 e (3) o culturas desenvolvidas em meio BRFS exibiu maior capacidade de inibição.

\section{INTRODUCCIÓN}

De Acuerdo con la FAO [1] un tercio de la producción de los alimentos destinados al consumo humano se pierde en todo el mundo, lo que equivale a más 1.300 millones de toneladas al año y se estima que un cuarto de la producción alimentaria mundial se pierde debido a las alteraciones causadas por microorganismos. Según el Departamento Nacional de Planeación (DNP), en Colombia se desperdicia el $34 \%$ de los alimentos destinados a consumo humano; se botan 9,76 millones de toneladas de alimentos por año y el $36 \%$ de esta cantidad se desperdicia en las etapas de distribución, venta al por menor y hogares. En los productos lácteos las pérdidas ascienden a 29 mil toneladas año [2]. La aparición de productos alimenticios deteriorados hace decrecer la confianza del consumidor y es causa de pérdidas económicas para empresas. Estas razones hacen que las industrias alimentarias se encuentren en continua búsqueda y desarrollo de nuevas tecnologías de conservación para alargar su vida útil y garantizar la inocuidad de sus productos.

Los derivados lácteos fermentados se caracterizan por proveer un sustrato favorable para el crecimiento de mohos y levaduras con la capacidad de fermentar azúcares (lactosa, glucosa, galactosa) e hidrolizar proteínas causando el deterioro de estos productos aun a temperaturas de refrigeración [3]. La contaminación del producto final por hongos presentes en el ambiente de plantas de producción, a pesar de las buenas prácticas de manufactura, es la primera causa de deterioro de productos lácteos. Durante su crecimiento, los hongos contaminantes alteran los derivados lácteos fermentados por la producción de diferentes tipos de sustancias como son compuestos volátiles y aromáticos y alcoholes entre otros que originan cambios de sabor, olor, textura y apariencia [4]. Los principales hongos causantes de alteraciones en productos lácteos fermentados son Mucor circinelloide, Meyerozyma guilliermondii, Candida parapsilosis, Candida diffluens, Debaryomyces hansenii, Kluyveromyces marxianus, Rhodotorula mucilaginosa, Yarrowia lipolytica, Zygosaccharomyces bailii o Penicillium brevicompactum y, si bien esto es un punto para analizar para cada producto, su aparición depende de varios factores, entre ellos la calidad de las materias primas, de los programas de higiene y desinfección y del ambiente de manufactura [5, 6]. Para la industria láctea, la prevención de la contaminación por microrganismos provenientes del ambiente para garantizar la vida útil y la inocuidad de los productos alimenticios y reducir las pérdidas económicas es un reto constante [3].

En los últimos años, la bioconservación o bioprotección ha generado particular interés como una alternativa natural al uso de conservantes artificiales para alargar la vida útil y para garantizar la inocuidad de los productos alimenticios; también, puede servir como seguro adicional para productos alimenticios refrigerados que no permiten la adición de conservantes tradicionalmente utilizados en la industria de alimentos, especialmente en regiones donde no se garantiza la cadena de frio [7]. La aplicación de microorganismos inocuos, así como de sus metabolitos con actividad antimicrobiana puede inhibir o retardar el crecimiento de flora microbiana deteriorativa y patógena $[7,8]$. Estos cultivos microbianos protectores de alimentos se componen principalmente de bacterias; son formulaciones que no solo contienen uno o más cultivos microbianos, también pueden estar presentes los metabolitos producidos durante su crecimiento o fermentación y compuestos necesarios para su estabilidad y aplicación en los correspondientes alimentos. Actualmente, la aplicación de cultivos bioprotectores y sus fermentados para reducir el deterioro de alimentos sigue creciendo en la industria de alimentos con la tendencia de etiquetado limpio o sea de productos naturales libres de aditivos y conservantes $[9,10,11]$. Los cultivos protectores pueden hacer parte de los cultivos microbianos iniciadores de fermentaciones al que también pertenecen los probióticos [12,13].

De acuerdo con la Asociación Europea de Alimentos y Cultivos Alimentarios (EFFCA), el concepto cultivos protectores se aplica a los cultivos alimentarios 
microbianos que, exhibiendo una actividad metabólica, contribuyen a inhibir o controlar el crecimiento de microorganismos indeseables en los alimentos sin cambiar sus propiedades tecnológicas y sensoriales $[12,13]$. Los cultivos protectores vivos en productos fermentados no requieren de declaración en Estados Unidos y, si se trata de cultivos protectores inactivos se declaran como "leche fermentada" o "azúcar fermentada" [12].

En la industria láctea, las bacterias ácido lácticas (BAL) y propiónicas (BAP) son ampliamente utilizadas en procesos fermentativos debido a sus características fisiológicas que aportan beneficios nutricionales así como tecnológicos a los derivados lácteos. Las BAL y las BAP son generalmente reconocidas como seguras (GRAS) y presunción cualificada de seguridad (QPS) por su largo historial de uso en la alimentación humana y animal. Estas bacterias pueden producir compuestos anti-fúngicos en virtud de su metabolismo $[14,15]$. Las BAL y las BAP son un grupo de bacterias Gram positivas morfológica y fisiológicamente heterogéneas. Durante sus procesos fermentativos de carbohidratos producen principalmente ácido láctico y propiónico pero también otros ácidos orgánicos, peróxido de hidrógeno, diacetil, dióxido de carbono, hidrógeno y péptidos antimicrobianos que contribuyen a su actividad antagónica contra hongos y bacterias $[3,16]$. Sin embargo, el mecanismo de acción de su actividad inhibitoria no se encuentra totalmente dilucidado para poder hacer un uso optimizado de su capacidad antimicrobiana [17]. El efecto y el mecanismo inhibitorio de las BAL y BAP contra bacterias patógenas se conoce mucho mejor que contra mohos y levaduras deteriorativas [18].

Actualmente se identifican los siguientes principales mecanismos de acción de los compuestos con actividad antimicrobiana [19]:

- Ácido láctico y otros ácidos volátiles: disrupción del metabolismo celular.

- Peróxido de hidrógeno: inactivación de biomoléculas esenciales por reacción en cadena de aniones superóxido y activación del sistema lactoperoxidasa.

- Dióxido de carbono: entorno anaerobio y/o inhibición de la decarboxilación enzimática y/o disrupción de la membrana celular.
- Diacetil: interferencia con la utilización de la arginina.

- Bacteriocinas: disrupción de la membrana citoplasmática.

Dentro del grupo de las BAL los géneros LactobaciIlus, Pediococcus y Leuconostoc han sido los más estudiados en relación con su actividad antifúngica [16, 18, 20]. La especie Propionibacterium freudenreichii es reconocida por sus propiedades antimicóticas dentro del grupo de las BAP [21]. El efecto antimicrobiano de bioprotectores ha sido estudiado con mayor intensidad con cultivos vivos y existe muy poca literatura científica sobre el efecto antimicrobiano de cultivos tratados térmicos.

Se reconoce ampliamente en la microbiología que las capacidades fisiológicas entre cepas pueden ser diferentes y, tanto su resistencia a agentes antimicrobianos como su capacidad antimicrobiana, no se escapan a esta realidad [10]. La aplicación de soluciones de bioprotección para el caso de bacterias patógenas está más extensamente referenciada en la literatura no así las aplicaciones sobre microrganismos deteriorativos de alimentos procesados [9].

En el procesamiento de derivados lácteos existen procesos que conllevan más de un tratamiento térmico y, por lo tanto, siempre existe la duda sobre la efectividad de cultivos bioprotectores a partir de células viables. El presente trabajo de investigación tuvo como propósito evaluar la capacidad antifúngica de diferentes cepas de cultivos bioprotectores sobre diferentes cepas de M. circinelloides y Geotrichum candidum mediante un escrutinio en modelos lácteos, el efecto del tratamiento térmico de cultivos bioprotectores sobre su capacidad inhibitoria y el efecto del medio de cultivo sobre la capacidad antimicótica.

\section{MÉTODO}

\section{Aislamiento e identificación de especies alterantes}

Para los aislamientos fúngicos se partió de derivados lácteos fermentados comerciales con presencia de mohos provenientes de la planta Sopó, Cundinamarca (altitud $2587 \mathrm{msnm}, 14^{\circ} \mathrm{C}$ ). Los aislamientos se realizaron mediante técnicas tradicionales en medios agar 
YPD (Yeast Extract Peptone Dextrose) y Sabouroub agar; una vez obtenido el primer crecimiento, se llevaron a cabo pases sucesivos para asegurar la pureza de los cultivos. Con los cultivos aislados se llevó a cabo la creación de un banco celular primario de esporas (50\% Glicerol + 0,005\% Tween80) a $-80^{\circ} \mathrm{C}$, y a partir del cual se continuó trabajando.

Para su identificación se utilizaron técnicas de biología molecular que incluyeron la extracción del ADN, la amplificación de las regiones intergénicas ITS (Internal Transcribed Spacer) mediante PCR (Polymerase Chain Reaction) utilizando los cebadores ITS4 e ITS5 de los genes ARNr. La identificación se realizó mediante análisis en bases de datos públicas utilizando la herramienta on line BLAST [22].

\section{Selección de los cultivos bioprotectores para las pruebas de antagonismo}

Se seleccionaron 9 cepas pertenecientes a las especies Lactobacillus rhamnosus, L. casei y el género Propionibacterium del cepario del centro biotecnológico ADM-Biopolis (España). Estos grupos fueron escogidos debido a que se ha descrito previamente actividad antifúngica en alguna cepa y por estar incluidos en el listado europeo de seguridad QPS (ver Cuadro 1).

\section{Elaboración de los productos celulares bioprotectores para los ensayos reto}

Se realizaron ensayos con distintas aproximaciones, en la que se varió el medio de cultivo y el estado de las células de cultivos bioprotectores. En relación con el medio de cultivo, se ensayó el me- dio industrial estándar del centro biotecnológico ADM-Biopolis, de calidad alimentaria y libre de productos de origen animal, y un medio de cultivo industrial en base láctea (leche). En el primer caso se ensayaron las células obtenidas de éste, mientras que en el segundo caso, los ensayos se realizaron con el cultivo total (base láctea más células), con lo que se analizó el efecto tanto de las células como de los productos de su metabolismo. Se evaluó adicionalmente el efecto antifúngico de los cultivos inactivados térmicamente por pasteurización $\left(74^{\circ} \mathrm{C}, 30 \mathrm{~min}\right)$. Las aproximaciones para los ensayos se resumen a continuación:

- Cepas crecidas en medio de cultivo estándar (libre de base láctea) activas.

- Cepas crecidas en medio de cultivo estándar (libre de base láctea) con tratamiento térmico posterior ("azúcar fermentada").

- Cepas crecidas en medio de cultivo de base láctea activas.

- Cepas crecidas en medio de cultivo de base láctea con tratamiento térmico posterior ("leche fermentada").

La Figura 1 muestra el diagrama de preparación de los productos celulares para su evaluación en los ensayos reto. Para cada una de las cepas incluidas en el cuadro 1, se llevó a cabo un crecimiento en dos medios de cultivo distintos, por un lado, el medio de cultivo que se utiliza en ADM-Biopolis para el crecimiento industrial de estos microorganismos, y por el otro lado leche entera. Los medios fueron los mismos para todas las cepas, si bien las temperaturas de creci-

Cuadro 1. Cepas bacterianas potencialmente bioconservantes para los ensayos reto.

\begin{tabular}{|c|c|}
\hline Cepas & Especies \\
\hline BPL0004 & \\
\cline { 1 - 1 } BPL0079 & Lactobacillus casei \\
\hline BPL0080 & \\
\hline BPL0008 & Lactobacillus rhamnosus \\
\hline BPL0015 & Propionibacterium freudenreichii subsp. shermanii \\
\hline BPL037 & Propionibacterium freudenreichii subsp. freudenreichii \\
\hline BPL0081 & \\
\hline BPL0082 & \\
\hline
\end{tabular}

Figura 1. Elaboración de los productos celulares bioprotectores para los ensayos reto.

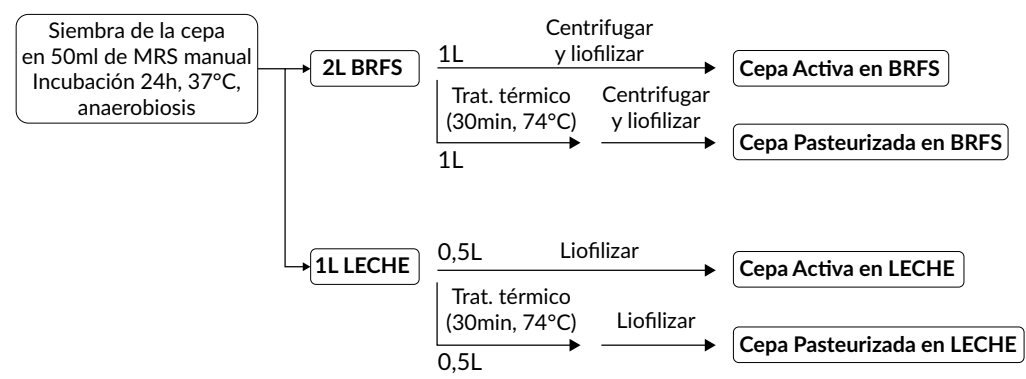


miento difirieron $\left(37^{\circ} \mathrm{C}\right.$ en el caso de lactobacilos, $30^{\circ} \mathrm{C}$ para propionibacterias). El medio BRFS está formulado para el crecimiento de bacterias lácticas y está compuesto por extractos proteicos, en particular, extracto de levadura, glucosa $(3-5 \% \mathrm{p} / \mathrm{v}$ dependiendo de la bacteria) y sales (fosfato dipotásico $0,3 \% \mathrm{p} / \mathrm{v}$, amonio hidrogenocitrato $0,2 \% \mathrm{p} / \mathrm{v}$, acetato sódico $0,5 \% \mathrm{p} / \mathrm{v}$, sulfato de magnesio $0,02 \% \mathrm{p} / \mathrm{v}$, sulfato de manganeso $0,003 \% \mathrm{p} / \mathrm{v}$ ).

Una vez realizados los crecimientos, se llevó a cabo un recuento en placa de los distintos cultivos. En el caso de las células activas en BRFS, éstas se recuperaron por centrifugación, se congelaron y liofilizaron. En el caso de las células inactivas, el cultivo se inactivó mediante tratamiento térmico $\left(74^{\circ} \mathrm{C}, 30 \mathrm{~min}\right)$, se recuperaron las células por centrifugación, se congelaron y liofilizaron. Para el caso de los preparados celulares en leche se manutuvo la base láctea de la matriz. Se realizaron recuentos de viables en todos los casos.

\section{Capacidad antifúngica de los productos celulares bioprotectores}

Los ensayos de reto se llevaron a cabo en medio sólido y para el estudio se seleccionó como medio de cultivo agar yogurt. Este medio se prepara mediante autoclavado del agar bacteriológico en agua, posterior atemperado a $50^{\circ} \mathrm{C}$ en baño y adición de yogur (previamente agitado y atemperado a $40^{\circ} \mathrm{C}$ en baño) en movimientos circulares.

Se realizó el escrutinio sobre la capacidad antifúngica de los preparados celulares bioprotectores sobre $M$. circinelloides y los distintos ensayos realizados fueron:

- Control de crecimiento del hongo alterante: medio agar yogur inoculado con los hongos alterantes.

- Ensayos de inhibición: medio agar yogur adicionado en profundidad con los distintos productos celulares a ensayar e inoculadas con los hongos alterantes.

- Control de contaminación: medio agar yogur adicionado de los productos ensayar.

Para asegurar la homogeneidad, los distintos productos celulares se adicionaron al yogur y se homogeneizaron antes de ser vertidos al agar. Una vez solidificados los medios de cultivo, se procedió a la inoculación de los distintos hongos alterantes. Las inoculaciones se realizaron por siembra en gota, a partir de soluciones de esporas glicerinadas y almacenadas a $-20^{\circ} \mathrm{C}$, en una concentración de 3 esporas $/ 10 \mu \mathrm{L}$. Las inoculaciones se realizaron con gotas de $10 \mu \mathrm{L}$ y posterior incubación a $28^{\circ} \mathrm{C}$.

La evaluación de la capacidad inhibitoria se realizó mediante medida del diámetro de crecimiento del hongo cada dos días. El ensayo se alargó hasta el momento en el que se dio un mismo diámetro en dos medidas consecutivas, o bien el cultivo alcanzó el diámetro de la placa.

\section{RESULTADOS}

\section{Identificación de las especies de mohos}

Se realizó la identificación de cinco aislados de las especies M. circinelloides y G. candidum. La Figura 2 muestra el crecimiento de los cinco aislados en agar Saboraud.

\section{Cuantificación de los productos celulares bioprotectores}

El Cuadro 2 muestra los resultados obtenidos de los recuentos bacterianos en los productos con y sin proceso térmico. Como puede observarse, el proceso de inactivación no fue completo en ninguno de los casos, aunque sí se produjeron reducciones en los recuentos de 3 a 10 unidades $\log _{10}$.

\section{Funcionalidad inhibitoria de los productos celulares bioprotectores}

Los productos celulares bioprotectores pasteurizados en términos generales no presentaron o tuvieron baja funcionalidad inhibitoria sobre los diferentes aislados de mohos comparado con los cultivos bioprotectores vivos. En el Cuadro 3 se resumió el desempeño de los productos celulares bioprotectores cultivados en medio BRFS sin y con Pasteurización. P. freudenrichii subsp. shermanii BPL0082 fue la cepa con mayor funcionalidad antifúngica presentando una inhibición de crecimiento alta sobre los cinco aislados de mohos. Las cepas de L. casei BPL0004, BPL0079 y BPL0080 tuvieron un efecto inhibitorio alto sobre los aislados de M. cicirnelloides, no así en general para G. candidum aunque para el aislado $\mathrm{H} 2$ las primeras dos cepas presentaron un efecto inhibitorio positivo y ligero respectivamente. Las cepas de $L$. rhamnosus y $P$. freuden- 
Figura 2. Aislados de mohos de productos lácteos fermentados comerciales. M. circinelloides (H1), G. candidum (H2), M. circinelloides (H3), G. candidum (H4), G. candidum (H5).

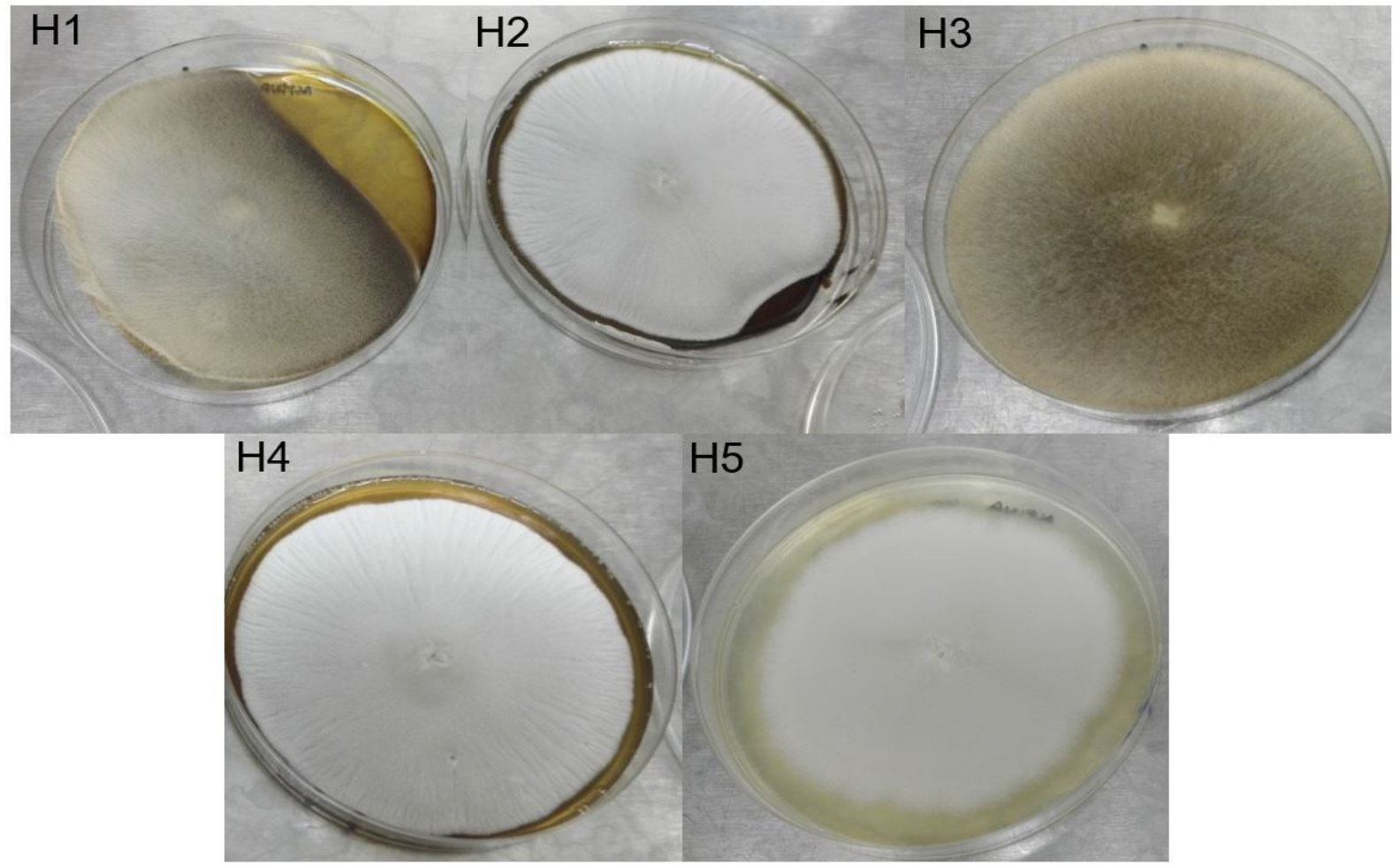

richii subsp. freudenrichii se caracterizaron por tener bajo o ningún poder antifúngico.

El Cuadro 4 contiene los resultados obtenidos con los productos celulares bioprotectores cultivados en leche tal como sucedió con los cultivados en medio BRFS, los productos bioprotectores pasteurizados no tuvieron un efecto antifúngico. La cepa de $P$. freudenrichii subsp. shermanii BPL0082 fue la de mejor desempeño inhibitorio, aunque sobre $M$. circinelloides presentó un efecto menor al compararlo con los resultados obtenidos en medio BRFS. Las cepas de L. casei BPL0004, BPL0079 y BPL0080 presentaron efecto inhibitorio alto sobre $M$. circinelloides. Entre las cepas de L. casei, solo la cepa BPL0004 tuvo efecto inhibitorio positivo sobre el aislado $\mathrm{H} 2$ de G. candidum. En medio de cultivo leche la cepa de L. rhamnosus BPL0037 inhibió de manera positiva y ligera los cinco aislados de mohos, efecto que no se observó cuando se cultivó en medio BRFS.

En ninguno de los ensayos reto se presentó inhibición total del crecimiento. Cuando se presentó, el efecto antifúngico para todas las cepas BAL y BAP fue más alto con los liófilos con mayores recuentos indicando que la pasteurización afecta el poder antimicrobiano de los productos celulares bioprotectores. Leyva Salas et al. [23] reportaron en su estudio que la actividad antifúngica decreció sustancialmente cuando los recuentos de los inóculos de bacterias bioprotectoras se redujeron de $10 \mathrm{E}+7$ a $10 \mathrm{E}+5$.

La respuesta no homogénea de los aislados fúngicos de una misma especie permite sugerir que los aislados podrían ser cepas diferentes con tolerancias diferentes a los productos celulares bioprotectores [10]. A partir de los resultados obtenidos, G. candidum presentó una mayor resistencia a los preparados celulares bioprotectores evaluados.

En la literatura científica se identifica una considerable cantidad de conocimiento alrededor del efecto antagónico de BAL y BAP sobre bacterias patógenas en los alimentos. Mucho menos conocimiento existe alrededor del efecto antifúngico de estas bacterias (BAP y BAP) sobre hongos deteriorativos de los alimentos. Este trabajo de investigación contribuye al avance del conocimiento en la tecnología de biopro- 
Cuadro 2. Recuentos obtenidos de los distintos liófilos para su posteriormente evaluación de su funcionalidad antifúngica.

\begin{tabular}{|c|c|c|}
\hline Cepa & Muestra & UFC/g liófilo \pm SD \\
\hline \multirow{4}{*}{ L. rhamnosus BPL0008 } & BRFS & $1,98 \mathrm{E}+11 \pm 1,77 \mathrm{E}+10$ \\
\hline & BRFS + Pasteurización & $1,87 \mathrm{E}+06 \pm 2,40 \mathrm{E}+05$ \\
\hline & Leche & $1,34 \mathrm{E}+09 \pm 1,41 \mathrm{E}+07$ \\
\hline & Leche + Pasteurización & $1,02 \mathrm{E}+09 \pm 1,63 \mathrm{E}+08$ \\
\hline \multirow{4}{*}{ L. rhamnosus BPL0015 } & BRFS & $2,33 \mathrm{E}+11 \pm 2,83 \mathrm{E}+09$ \\
\hline & BRFS + Pasteurización & $9,00 E+01 \pm 0,00 E+00$ \\
\hline & Leche & $7,45 \mathrm{E}+01 \pm 1,48 \mathrm{E}+09$ \\
\hline & Leche + Pasteurización & $4,35 E+06 \pm 7,07 E+04$ \\
\hline \multirow{4}{*}{ L. rhamnosus BPL0037 } & BRFS & $1,70 \mathrm{E}+11 \pm 1,41 \mathrm{E}+09$ \\
\hline & BRFS + Pasteurización & $6,80 \mathrm{E}+03 \pm 1,41 \mathrm{E}+02$ \\
\hline & Leche & $8,10 E+09 \pm 8,49 E+08$ \\
\hline & Leche + Pasteurización & $1,12 \mathrm{E}+09 \pm 1,24 \mathrm{E}+08$ \\
\hline \multirow{4}{*}{ L. casei BPL0004 } & BRFS & $3,75 \mathrm{E}+10 \pm 7,78 \mathrm{E}+09$ \\
\hline & BRFS + Pasteurización & $6,25 \mathrm{E}+05 \pm 2,12 \mathrm{E}+04$ \\
\hline & Leche & $6,45 E+09 \pm 4,95 E+08$ \\
\hline & Leche + Pasteurización & $3,15 E+02 \pm 7,07 E+00$ \\
\hline \multirow{4}{*}{ L. casei BPL0079 } & BRFS & $1,12 \mathrm{E}+11 \pm 5,66 \mathrm{E}+09$ \\
\hline & BRFS + Pasteurización & $6,60 \mathrm{E}+07 \pm 5,66 \mathrm{E}+06$ \\
\hline & Leche & $9,00 \mathrm{E}+09 \pm 4,24 \mathrm{E}+08$ \\
\hline & Leche + Pasteurización & $3,65 \mathrm{E}+02 \pm 4,31 \mathrm{E}+02$ \\
\hline \multirow{4}{*}{ L. casei BPL0080 } & BRFS & $1,18 \mathrm{E}+11 \pm 1,02 \mathrm{E}+10$ \\
\hline & BRFS + Pasteurización & $7,75 \mathrm{E}+02 \pm 7,07 \mathrm{E}+00$ \\
\hline & Leche & $1,32 \mathrm{E}+09 \pm 6,22 \mathrm{E}+07$ \\
\hline & Leche + Pasteurización & $1,32 \mathrm{E}+02 \pm 6,36 \mathrm{E}+02$ \\
\hline \multirow{4}{*}{ P. freudenrichii subsp. shermanii BPL0081 } & BRFS & $1,44 \mathrm{E}+11 \pm 2,33 \mathrm{E}+10$ \\
\hline & BRFS + Pasteurización & $1,17 \mathrm{E}+05 \pm 4,00 \mathrm{E}+04$ \\
\hline & Leche & $5,58 \mathrm{E}+09 \pm 1,06 \mathrm{E}+08$ \\
\hline & Leche + Pasteurización & $9,55 \mathrm{E}+07 \pm 4,95 \mathrm{E}+06$ \\
\hline \multirow{4}{*}{ P. freudenrichii subsp. shermanii BPL0081 } & BRFS & $1,19 E+08 \pm 5,66 E+06$ \\
\hline & BRFS + Pasteurización & $3,00 \mathrm{E}+03 \pm 8,49 \mathrm{E}+02$ \\
\hline & Leche & $4,95 \mathrm{E}+07 \pm 6,36 \mathrm{E}+04$ \\
\hline & Leche + Pasteurización & $4,45 \mathrm{E}+04 \pm 7,78 \mathrm{E}+03$ \\
\hline \multirow{4}{*}{ P. freudenrichii subsp. freudenrichii BPL0083 } & BRFS & $3,80 \mathrm{E}+07 \pm 4,24 \mathrm{E}+06$ \\
\hline & BRFS + Pasteurización & $1,45 \mathrm{E}+03 \pm 4,95 \mathrm{E}+02$ \\
\hline & Leche & $7,20 \mathrm{E}+07 \pm 1,41 \mathrm{E}+06$ \\
\hline & Leche + Pasteurización & $1,23 E+06 \pm 3,54 E+04$ \\
\hline
\end{tabular}


Cuadro 3. Efecto antifúngico de los productos celulares bioprotectores BRFS sin y con Pasteurización posterior. M. circinelloides ( $\mathrm{H} 1)$, G. candidum (H2), M. circinelloides (H3), G. candidum (H4), G. candidum (H5).

\begin{tabular}{|c|c|c|c|c|c|c|}
\hline Especies & Cepas & $\mathrm{H} 1$ & $\mathrm{H} 2$ & H3 & $\mathrm{H} 4$ & $\mathrm{H} 5$ \\
\hline \multirow{6}{*}{ Lactobacillus casei } & BPL0004 & ++ & + & ++ & - & - \\
\hline & BPL0004* & - & - & - & - & - \\
\hline & BPL0079 & ++ & $(-)$ & ++ & - & - \\
\hline & BPL0079* & - & - & - & - & - \\
\hline & BPL0080 & ++ & - & ++ & - & - \\
\hline & BPL0080* & - & - & - & - & - \\
\hline \multirow{6}{*}{ Lactobacillus rhamnosus } & BPL0008 & - & - & $(-)$ & - & $(-)$ \\
\hline & BPL0008* & - & - & - & - & - \\
\hline & BPL0015 & - & - & - & - & - \\
\hline & BPL0015* & - & - & - & - & - \\
\hline & BPL0037 & $(-)$ & $(-)$ & $(-)$ & $(-)$ & $(-)$ \\
\hline & BPL0037* & - & - & - & - & $(-)$ \\
\hline \multirow{4}{*}{$\begin{array}{l}\text { Propionibacterium freudenreichii } \\
\text { subsp. shermanii }\end{array}$} & BPL0081 & - & $(-)$ & - & $(-)$ & $(-)$ \\
\hline & BPL0081* & - & - & - & - & - \\
\hline & BPL0082 & ++ & ++ & ++ & ++ & ++ \\
\hline & BPL0082* & - & - & - & - & - \\
\hline \multirow{2}{*}{$\begin{array}{l}\text { Propionibacterium freudenreichii } \\
\text { subsp. freudenreichii }\end{array}$} & BPL0083 & - & - & - & - & - \\
\hline & BPL0083* & - & - & $(-)$ & - & - \\
\hline
\end{tabular}

* con Pasteurización

++ Inhibición de crecimiento alta, + inhibición de crecimiento positiva, (-) inhibición de crecimiento baja, - Inhibición de crecimiento negativa.

Cuadro 4. Efecto antifúngico de los productos celulares bioprotectores en leche sin y con Pasteurización posterior. M. circinelloides (H1), G. candidum (H2), M. circinelloides (H3), G. candidum (H4), G. candidum (H5).

\begin{tabular}{|c|c|c|c|c|c|c|}
\hline Especies & Cepas & H1 & $\mathrm{H} 2$ & H3 & $\mathrm{H} 4$ & H5 \\
\hline \multirow{6}{*}{ Lactobacillus casei } & BPL0004 & ++ & + & ++ & - & - \\
\hline & BPL0004* & - & - & - & - & - \\
\hline & BPL0079 & ++ & - & ++ & - & - \\
\hline & BPL0079* & - & - & - & - & - \\
\hline & BPL0080 & ++ & - & ++ & - & - \\
\hline & BPL0080* & - & - & - & - & - \\
\hline \multirow{6}{*}{ Lactobacillus rhamnosus } & BPL0008 & - & - & $(-)$ & - & - \\
\hline & BPL0008* & - & - & - & - & - \\
\hline & BPL0015 & - & $(-)$ & - & - & - \\
\hline & BPL0015* & - & - & - & - & - \\
\hline & BPL0037 & $(-)$ & + & + & + & + \\
\hline & BPL0037* & - & - & - & - & - \\
\hline \multirow{4}{*}{$\begin{array}{l}\text { Propionibacterium freudenreichii } \\
\text { subsp. shermanii }\end{array}$} & BPL0081 & - & $(-)$ & - & $(-)$ & + \\
\hline & BPL0081* & - & - & - & - & $(-)$ \\
\hline & BPL0082 & + & ++ & + & ++ & ++ \\
\hline & BPL0082* & - & - & + & ++ & $(-)$ \\
\hline \multirow{2}{*}{$\begin{array}{l}\text { Propionibacterium freudenreichii } \\
\text { subsp. freudenreichii }\end{array}$} & BPL0083 & - & - & $(-)$ & - & - \\
\hline & BPL0083* & - & - & - & - & - \\
\hline
\end{tabular}

* con Pasteurización

++ Inhibición de crecimiento alta, + inhibición de crecimiento positiva, (-) inhibición de crecimiento baja, - Inhibición de crecimiento negativa. 
tección, especialmente en la medida que aporta resultados sobre el efecto de los tratamientos térmicos y del medio de crecimiento de los cultivos bioprotectores sobre la capacidad inhibitoria.

\section{CONCLUSIONES}

La aplicación de soluciones de bioprotección para la industria de alimentos, que garantice la inocuidad y el deterioro de los productos alimenticios, sigue creciendo con las tendencias de mercado por productos alimenticios naturales y con etiquetas limpias. Actualmente, se investiga intensamente sobre la aplicación de cultivos bioprotectores o sus fermentados para terminar de entender su mecanismo de acción y los factores que afectan su función antimicrobiana para así poder optimizar su aplicación. Los resultados del presente estudio permitieron concluir que las cepas bacterianas de una misma especie de BAL o BAP tienen funcionalidad antifúngica diferente, que los aislados de mohos pueden tener tolerancias diferentes, que los aislados de $G$. candidum presentaron una mayor resistencia a las soluciones bioprotectoras, que la Pasteurización reduce el efecto inhibitorio de los cultivos bioprotectores y que el medio de cultivo para el crecimiento de las BAL y BAP influye en su poder bioprotector.

\section{AGRADECIMIENTOS}

Agradecimientos a ADM-Biopolis por su contribución en la ejecución de este estudio.

\section{REFERENCIAS}

[1] ORGANIZACIÓN DE LAS NACIONES UNIDAS PARA LA AGRICULTURA Y LA ALIMENTACIÓN (FAO). Pérdidas y desperdicio de alimentos en el mundo - Alcance, causas y prevención. Roma. 2012. http://www.fao.org/docrep/016/ i2697s/i2697s.pdf. [citado 8 octubre 2017]

[2] COLOMBIA. DEPARTAMENTO DE PLANEACIÓN NACIONAL (DNP). 2016 https:// www.dnp.gov.co/Paginas/Colombianos-botan-9,76-millones-de-toneladas-de-comida-ala\%C3\%B1o.aspx. [citado 10 octubre 2017]

[3] DELAVENNE, E. et al. Assessment of lactobacilli strains as yogurt bioprotective cultures.
Food Control, 30(1), 2013, p. 206-213. doi: 10.1016/j.foodcont.2012.06.043.

[4] ROUSE, S. et al. Lactic acid bacteria with potential to eliminate fungal spoilage in foods. Journal of Applied Microbiology, 104(3), 2008, p. 915 23. doi: 10.1111/j.1365-2672.2007.03619.x.

[5] LEDENBACH, L.H. and MARSHALL, R.T. Microbiological spoilage of dairy products. Compendium of the Microbiological Spoilage of Foods and Beverages, Food Microbiology and Food Safety. New York (USA): Springer, 2009, p. 4167. doi: 10.1007/978-1-4419-0826-1_2.

[6] PAL, M. Spoilage of dairy products due to fungi. Beverage and Food World, 41(7), 2015, p. 37-38.

[7] YUSUF, M. Natural antimicrobial agents for food preservation. Food Packaging and Preservation, 12, 2018, p. 409-438. doi: 10.1016/ B978-0-12-811516-9.00012-9

[8] GHANBARI, M. et al. Seafood biorpreservation by lactic acid bacteria - A review. Food Science and Technology, 54, 2013, p. 315-324. doi:10.1016/B978-0-12-811516-9.00012-9

[9] DOKKA, A. et al. Protective cultures - A review. International Journal of Current Microbiology and Applied Sciences, 7(6), 2018, p. 228-238. doi:10.20546/ijcmas.2018.706.028

[10] GARNIER, L. et al. Diversity and control of spoilage fungi in dairy products: An update. Microorganisms, 5(3), E42. 2017. doi: 10.3390/ microorganisms 5030042 .

[11] LEYVA-SALAS, M. et al. Antifungal microbial agents for food biopreservetion: $\mathrm{A}$ review. Microorganisms, 5(3), 37, 2017. doi: 10.3390/microorganisms 5030037.

[12] CLERICI-SACCO GROUP. Protective cultures in the food industry. 2016. http://users.unimi. it/dmora/materiali/BiotecFerm/ProtectCultures-DalBello.pdf. [citado 10 de octubre 2017]

[13] EUROPEAN FOOD AND FEED CULTURES ASSOCIATION (EFFCA). Traditional use of the protective properties of food cultures. 2016. http://www.effca.org/sites/default/files/Traditional\%20use\%20of\%20the\%20protecive\%20 properties $\% 20$ of $\% 2$ food $\% 20$ cultures $\% 20$ NOV\%202016.pdf. [citado 10 de octubre 2017]

[14] FERNANDEZ, B. et al. Antifungal activity of lactic and propionic acid bacteria and their potential as protective culture in cottage cheese. Food Control, 78, 2017, p. 350-356. doi: 10.1016/j.foodcont.2017.03.007 
[15] LEYVA-SALAS, M. Antifungal lactic acid bacteria combinations as biopreservation tool in cheese production. The $10^{\text {th }}$ Cheese Symposium. Rennes (France): 2018.

[16] DALIÉ, D. et al. Lactic acid bacteria -Potential for control of mould growth and micotoxins: A review. Food Control, 21, 2010, p. 370-380. doi: DOI:10.1016/j.foodcont.2009.07.011

[17] HEREU, A. et al. High hydrostatic pressure and biopreservation of dry-cured ham to meet the Food Safety objectives for Listeria monocytogenes. International Journal of Food Microbiology, 154(3), 2012, p. 107-112. doi:10.1016/j.ijfoodmicro.2011.02.027

[18] CROWLEY, S. et al. Comparative analysis of two antifungal Lactobacillus plantarum isolates and their application as bioprotectants in refrigerated foods. Journal of Applied Microbiology, 113, 2012, p. 1417-1427. doi:10.1111/jam.12012

[19] SIEDLER, S., BALTI, R. and NEVES, A. Bioprotective mechanism of lactic acid bacteria against fungal spoilage of food. Current Opinion in Biotechnology, 56, 2019, p. 138-146. doi.org/10.1016/j.copbio.2018.11.015.

[20] SCHNÜRER, J. and MAGNUSSON, J. Antifungal lactic acid bacteria as biopreservatives. Trends in Food Science \& Technology, 16(1-3), 2005, p. 70-78. doi:10.1016/j.tifs.2004.02.014

[21] LE LAY, C. et al. Identification and quantification of antifungal compounds produced by lactic acid bacteria and propionibacteria. International Journal of Food Microbiology, 239, 2016, p.7985. doi: 10.1016/j.ijfoodmicro.2016.06.020

[22] BASIC LOCALALIGNMENT SEARCH TOOL (BLAST). 2018. https://blast.ncbi.nlm.nih.gov/Blast.cgi

[23] LEYVA-SALAS, M., et al. Antifungal activity of lactic acid bacteria combinations in dairy mimicking models and their potential as bioprotective cultures in pilot scale applications. Frontiers in Microbiology, 6, 1787, 2018. doi: 10.3389/fmicb.2018.01787. 